\title{
More on Decentralization and Economic Growth*
}

\author{
Henry Aray ${ }^{\dagger}$ \\ University of Granada
}

July, 2016

\begin{abstract}
This article casts new evidence on the effects of decentralization on economic growth. Based on the literature on the effects of institutions on the economy, such effects are assumed to accrue through total factor productivity $(T F P)$. We try to overcome the recent criticisms of the empirical approaches regarding the proper measures of variables capturing decentralization. Thus, five variables to capture decentralization are proposed. Panel data for the regions of Spain over the 1986-2010 period are used. The results show that the financial autonomy and the share of regional investment in public infrastructure seem to positively affect the economic growth of Spanish regions. However, a negative effect is found for the number of responsibilities transferred to the regions. Moreover, the empirical evidence could be suggesting that the Spanish state might be near or surrounding the optimal level of decentralization. Results are fairly robust to different estimation methods and measures of TFP, regardless of the assumption of constant returns to scale.
\end{abstract}

Key words: Decentralization; TFP; Spain; Panel Data.

JEL Classification: O43; H77; C33.

*Financial support from Fundación Centro de Estudios Andaluces through project PRY108/14 is gratefully acknowledged.

${ }^{\dagger}$ Corresponding author: Department of Economics. Facultad de Ciencias Económicas y Empresariales. Campus de la Cartuja S/N, 18011, Granada, Spain. e-mail: haray@ugr.es. Phone: +34958241000 ext. 20140 Fax: +34958 244218. 


\section{Introduction}

Since the late nineties, there has been a great interest among scholars in the effects of decentralization on the economy, mainly motivated by the increasing degree of decentralization in many countries over the past three decades.

The process of decentralization is usually justified by the "closeness" or "greater awareness of the needs of citizens," which is usually attributed to local or regional planners who are supposed to know these needs better, so that, in principle, they would be more efficient in satisfying them (Tiebout, 1956 and Oates, 1972, 1999). According to this view, decentralizing a state through ceding decision-making powers to regions accompanied by increasing autonomy in the management of revenues and expenses would produce higher efficiency in the provision of public goods and services and hence higher economic growth. However, the literature has not yet led to a clear conclusion in this regard as shown in the empirical evidence collected by Martínez-Vázquez (2003), Martínez-Vázquez et al. (2015) and Baskaran et al. (2016). Moreover, the empirical evidence seems to be in line with theoretical research suggesting the possible existence of a threshold or optimal level of decentralization. Xie et al. (1999) developed an endogenous growth model to demonstrate how decentralization affects the growth rate in the long run. They calibrated the model for the US economy and found 
that the proportion of expenditure undertaken by states and municipalities is consistent with the maximum growth rate, indicating that increasing this ratio would produce a decline in growth. Akai et al. (2007) also reported the existence of an optimal level of decentralization that maximizes the growth rate. The works of Ogawa and Yakita (2009) and Chu and Yang (2012) are along the same lines. They suggest that the optimal level of decentralization that maximizes the growth rate is higher than that generating the maximum welfare.

In this article, decentralization is not defined in political terms, but in economic terms. Nevertheless, economic decentralization could presumably follow a process of political decentralization. In line with the literature, we therefore refer to fiscal decentralization as the process by which greater responsibilities and powers are granted to the regions with regard to revenues and expenses (i.e., granting greater autonomy in the management of public resources) as well as the concession of decision-making powers regarding political, legal, administrative and economics affairs.

The article will focus specifically on Spain; one of most decentralized European countries alongside Switzerland, Germany and Belgium, ${ }^{1}$ and it tests the effects that decentralization could have on the economic growth of Spanish regions for which empirical evidence is scarce. Using only measures based on revenues, Gil-Serrate and López-Laborda (2006) and Gil-Serrate

\footnotetext{
${ }^{1} \mathrm{~A}$ good analysis of the decentralization process in Spain can be found in Moreno (2002) and Carrion-i-Silvestre et al. (2008).
} 
et al. (2011) found positive effects. Carrion-i-Silvestre et al. (2008) found positive effects for both expenditure and revenue measures of decentralization for regions with higher levels of competencies according to the framework that was establish for the statutes of autonomy, while negative effects for regions with less responsibilities were found. ${ }^{2}$ Cantarero and PérezGonzález (2009) found no evidence of an expenditure decentralization effect on economic growth. However, they did find empirical support for a positive relationship between revenue decentralization and economic growth. Aray (2016) incidentally found no significant statistical evidence.

The proposed methodology differs from the previous literature in the following. First, it follows the literature on institutions and economic growth (North, 1990; Hall and Jones, 1999; Rodrick, 2004 and Dixit, 2009) and assumes that the effects of decentralization on economic growth accrue through total factor productivity $(T F P)$. Second, since this literature is recent, as mentioned above, one of the usual criticisms of the empirical implementations refers to the measures used to account for decentralization as recently pointed out by Martínez-Vazquez et al. (2015) and Ligthart and van Oudheusden (2016). Therefore, this article tries to overcome the recent criticisms of the empirical approach regarding the proper measures of

\footnotetext{
${ }^{2}$ To classify the autonomous communities (ACs) according to their competencies, they rely on the route taken to achieve autonomy, which may be either the route indicated in Article 143 or Article 151 of the Spanish constitution and the so-called foral ACs. Thus, the first have the lowest competencies, followed by the second and the foral ACs, which have the highest competencies according to that clasification.
} 
variables capturing decentralization. Thus, five measures of decentralization are proposed to capture tax autonomy, financial autonomy, public investment autonomy and the general decision-making power in order to better reflect the heterogeneous degree of decentralization across the regions of Spain.

The suitability of this article is justified precisely because decentralization is a constant issue in the political debate in Spain. Recently, it has become one of the hottest topics as a result of Catalonia's claim for independence, which has added more pressure on the central government, aside from the habitual call by some regions for greater self-government. Moreover, statements by some politicians have added even more controversy to the ongoing political debate. On the one hand, some of them point to the need to advance in the management of resources by the regions, suggesting moving towards a federal state. On the other hand, others suggest a reversal in the decentralization process to return some responsibilities to the central government (i.e., a more centralized state than the current one, arguing that decentralization has led to an increase in the bureaucracy or the duplicity of some functions). What is striking about both viewpoints is that they are based on the same argument, that is, to increase regions' efficiency, economic growth and welfare.

The methodology used to achieve the main objective is based on the specification of a behavioral equation for the growth rate of TFP. We consider the Spanish case at two layers of government (central and regional) 
for the 1986-2010 period and all the autonomous communities of Spain ${ }^{3}$. Panel data estimation is applied.

The empirical results show that increasing the financial autonomy of the regions, as well as allocating a greater share of the regional investment to public infrastructure, positively affect the growth rate of $T F P$, while this indicator is negatively affected by the number of responsibilities or competencies assumed by the autonomous communities.

A matter of concern in this article is the robustness of the results in the empirical implementation. First, the dependent variable, the growth rate of $T F P$, is estimated through a growth accounting exercise. Second, we alternatively obtain econometric measures of $T F P$ growth by estimating Cobb-Douglas production functions. Third, a large enough set of control variables is included, and fourth, different methods of estimations are used: panel data regression with fixed and random effects and two-step least squares (2SLS).

The objective of this article could be interesting not only for Spain, but also at the European level due to the resurgence of regional policies to reduce disparities between European regions.

The article is organized as follows. The econometric model is presented in the next section and estimation issues are described in section 3. Section 4 shows robustness checks, while conclusions are drawn in section 5 .

\footnotetext{
${ }^{3}$ The term "autonomous communities" refers to a set of territories that do not all share the same characteristics and have different levels of decision making.
} 


\section{Empirical Strategy}

We use the approach of Aray (2016) and consider that the final output of region $i$ in year $t, Y_{i t}{ }^{4}$ be given by a Cobb-Douglas production function with constant return to scale such that

$$
Y_{i t}=B_{i t} K_{i t}^{\alpha_{i t}} N_{i t}^{1-\alpha_{i t}}
$$

where $K_{i t}$ is the stock of non-residential productive physical capital, $N_{i t}$ is the number of efficient workers (stock of human capital) provided by the BBVA Foundation and the Valencian Institute of Economic Research (BBVAIVIE). $\alpha_{i t}$ and $1-\alpha_{i t}$ are the capital and labor shares, respectively, and $B_{i t}$ is the TFP when labor is adjusted for human capital.

The production per efficient worker is

$$
y_{i t}=B_{i t} k_{i t}^{\alpha_{i t}}
$$

where $k_{i t}$ is the annual stock of non-residential productive physical capital per efficient worker.

TFP evolves over time according to a function as follows: ${ }^{5}$

\footnotetext{
${ }^{4}$ Value added at factor cost is used, which is taken from the National Statistics Institute of Spain (INE). Constant values were also constructed using data from the INE.

${ }^{5}$ As in Cantarero and Pérez-González (2009), a nonlinear relation between economic growth and decentralization is suggested.
} 


$$
\begin{aligned}
\frac{B_{i t}}{B_{i t-1}}= & \frac{Z_{i t}}{Z_{i t-1}}\left(\frac{S I_{i t}}{S I_{i t-1}}\right)^{\theta_{1}}\left(\frac{k_{i t}^{p u}}{k_{i t-1}^{p u}}\right)^{\theta_{2}}\left(\frac{k_{i t}^{h c}}{k_{i t-1}^{h c}}\right)^{\theta_{3}}\left(\frac{k_{i t}^{s}}{k_{i t-1}^{s}}\right)^{\theta_{4}}\left(\frac{k_{i t}^{r d}}{k_{i t-1}^{i d}}\right)^{\theta_{5}} \times \\
& \left(\frac{T A_{i t}}{T A_{i t-1}}\right)^{\beta_{1}}\left(\frac{F A_{i t}}{F A_{i t-1}}\right)^{\beta_{2}}\left(\frac{I A_{i t}^{p u}}{I A_{i t}^{p u}}\right)^{\beta_{3}}\left(\frac{I A_{i t}^{e h}}{I A_{i t}^{e h}}\right)^{\beta_{4}}\left(\frac{N R_{i t}}{N R_{i t-1}}\right)^{\beta_{5}}(2)
\end{aligned}
$$

Where

$$
\frac{Z_{i t}}{Z_{i t-1}}=e^{\left(\delta_{i}+\tau_{t}+\sum_{p=0}^{2} \theta_{M p} D M_{i t-p}+\varepsilon_{i t}\right)}
$$

The growth rate of $T F P$ is given by

$$
\begin{aligned}
\triangle \log \left(B_{i t}\right)= & \delta_{i}+\tau_{t}+\sum_{p=0}^{2} \theta_{M p} D M_{i t-p}+\theta_{1} \triangle \log \left(S I_{i t}\right)+\theta_{2} \triangle \log \left(k_{i t}^{p u}\right) \\
& +\theta_{3} \triangle \log \left(k_{i t}^{h c}\right)+\theta_{4} \triangle \log \left(k_{i t}^{s}\right)+\theta_{5} \triangle \log \left(k_{i t}^{r d}\right) \\
& +\beta_{1} \Delta \log \left(T A_{i t}\right)+\beta_{2} \triangle \log \left(F A_{i t}\right)+\beta_{3} \triangle \log \left(I A_{i t}^{p u}\right) \\
& +\beta_{4} \triangle \log \left(I A_{i t}^{e h}\right)+\beta_{5} \triangle \log \left(N R_{i t}\right)+\varepsilon_{i t}
\end{aligned}
$$

Where $\delta_{i}$ is a specific regional effect that captures unobservable characteristics of region $i$ and $\tau_{t}$ is a time effect that captures unobservable characteristics which equally affect all regions over time.

Let us start by describing the set of variables that have been assumed and shown to influence the TFP growth rate, which are the controllers in this estimation.

$D M_{i t}$ is a dummy variable that captures the partisan alignment effect with a majority in the central government, and zero otherwise, as suggested 
by Aray (2016) who found a positive contemporaneous partisan alignment effect and negative lagged partisan alignment effects until two periods. This variable has been constructed based upon RULERS, World Statesmen.org and the Spanish Ministry of Home Affairs (Ministerio del Interior). ${ }^{6,7}$

$S I_{i t}$ is a specialization index as specified by Álvarez (2007) that accounts for the different economic structure of the regions with respect to the whole country. The index is defined as follows

$$
S I_{i t}=\sum_{j=1}^{5}\left(\frac{Y_{i t, j}}{Y_{i t}}-\frac{\mathbf{Y}_{t, j}}{\mathbf{Y}_{t}}\right)^{2}
$$

$Y_{i t, j}$ is the gross value added of sector $j$ in region $i$ in year $t, Y_{i t}$ is the total gross value added of region $i$ in year $t$ as defined above and $\mathbf{Y}_{t, j}$ and $\mathbf{Y}_{t}$ stand for values added referring to Spain. Subscript $j$ denotes the following sectors: agriculture, industry, energy, construction and services. These variables are calculated using INE data. If $S I_{i t}$ is zero, the regional productive structure is equal to that of the whole country and increases in $S I_{i t}$ means more specialization.

$k_{i t}^{p u}$ is a variable accounting for annual stock of regional public

\footnotetext{
${ }^{6}$ Sources can be found in www.rulers.com, www.worldstatesmen.org and www.interior.gob.es. Since the first year of governance does not cover the whole year, if the period of governance in any level of government starts after June, this variable takes the value zero in that year and one when it starts before June.

${ }^{7}$ Aray (2016) also introduced agglomeration and congestion effects and found no statistical evidence. Moreover, Martínez-Galarraga et al. (2008) showed evidence of agglomeration effects in Spain over time. However, they pointed out that the effects seemed to fall sharply from the mid-nineteenth century until late in the twentieth century. Specifically, they highlighted that, according to their results, there appears to be no evidence of agglomeration effects in the period 1985-1999.
} 
infrastructure per efficient worker, with the stock of public infrastructure $\left(K_{i t}^{p u}\right)$ provided by BBVA-IVIE. "Core infrastructure" is considered, which includes streets and highways, water systems, railways, airports, ports and other urban infrastructures provided by local governments. ${ }^{8}$

$k_{i t}^{h c}$ is a variable accounting for annual stock of public health care capital per efficient worker, with health care public capital $\left(K_{i t}^{h c}\right)$ provided by BBVAIVIE. ${ }^{9}$ A good health care system is related to healthy people, that is, more productive workers.

$k_{i t}^{s}$ is an index of social capital per worker of region $i$ in time $t$ provided by BBVA-IVIE.

$k_{i t}^{r d}$ is the stock of $\mathrm{R} \& \mathrm{D}$ capital per efficient worker with $K_{i t}^{r d}$ being the stock of R\&D capital of region $i$ in time $t$, provided by BD.MORES. ${ }^{10}$

Five explanatory variables are included to capture the effects of decentralization as described below.

$T A_{i t}$ is a variable that captures the tax autonomy of the regions. This variable is calculated as the share of the own taxes and ceded or assigned taxes collected by region $i$ and time $t$ over the total taxes collected by the central and regional government in region $i$ and time $t$. Therefore, this is simply a variable that captures the power that a region has to collect tax.

\footnotetext{
${ }^{8}$ These correspond to classifications $111,222,333,444,555$ and 600 according to the new BBVA-IVIE methodology to calculate public capital stock.

${ }^{9}$ This corresponds to item number 800 of the public capital stock.

${ }^{10}$ BD.MORES is an unofficial database provided by the Spanish Ministery of Finance and Public Administrations. It is widely used by researchers on the Spanish regional economy.
} 
$F A_{i t}$ refers to financial autonomy. It is measured as the share over the total non-financial resources of the autonomous community of the aforementioned taxes plus the part of the VAT and income taxes collected in region $i$ in year $t$ by the central administration and is transferred to the regional administration under the financial law of autonomous communities (LOFCA). Hence, the autonomous communities have available revenues in their budgets that they manage at their discretion. This variable differs from the previous one in that it effectively captures the capacity that a region has to autonomously allocate its revenues. $T A_{i t}$ and $F A_{i t}$ were calculated using data provided by the Spanish Public Sector Database (Base de Datos del Sector Público Español, BADESPE) $\cdot{ }^{11}$

$I A_{i t}^{p u}$ is the investment autonomy indicator for public infrastructure, calculated as the share of investment in public infrastructure of the autonomous communities and the local governments on total public investment in infrastructure in region $i$ in year $t$, where public infrastructure is defined as above. ${ }^{12}$

$I A_{i t}^{e h}$ is the investment autonomy indicator for education and health, calculated as the share of public investment in infrastructure in education and health of the autonomous communities and the local governments over total public investment in education and health in region $i$ in year $t{ }^{13}$

\footnotetext{
${ }^{11}$ The data can be accessed at www.estadief.meh.es.

${ }^{12}$ It includes items 102, 103, 202 and 203 of the public investment series of the BBVAIVIE.

${ }^{13}$ It includes items 702, 703, 802 and 803 of the public investment series of the BBVA-
} 
$N R_{i t}$ can be understood as a general variable that captures the political, legal, administrative and economic decision-making power of the regions. The numbers of responsibilities ceded to region $i$ in time $t$ under the royal decrees on the transfer of competencies are used, which are provided by the Ministry of Finance and Public Administrations (Ministerio de Hacienda y Administraciones Públicas). ${ }^{14}$ The competencies ceded or assigned to a region are formally framed in the statutes of autonomies of the regions. However, the royal decrees on the transfer of competencies are the legal tools that determine the time at which the autonomous community becomes responsible for the competencies, such as the provision of services or any other responsibilities that previously corresponded to the central government, as well as new competencies set out under the statutes. Therefore, it is when a royal decree is issued that a competence is effectively assumed by the autonomous community. This is the legal framework that has been designed to transfer competencies from the central administration to the regional administrations. These royal decrees are also very useful in specifying and defining the reach of the competencies assumed in the statutes. ${ }^{15}$

We consider that the variables described above are intended to capture the different degree of decentralization across the Spanish regions.

\footnotetext{
IVIE.

${ }^{14}$ The data can be accessed at www.seap.minhap.gob.es/index.html.

${ }^{15}$ The royal decrees aim at setting the material, personal and financial resources that were previously provided by the state and that will be assumed by the autonomous communities.
} 
Finally, $\varepsilon_{i t}$ is an iid disturbance.

The dependent variable $\triangle \log \left(B_{i t}\right)$ is calculated by performing a standard growth accounting exercise as Aray (2016).

\section{Estimation Issues}

Annual data over the 1986-2010 period are used to estimate equation (3). All the regions of Spain (autonomous communities, NUTS2) are included: ${ }^{16}$ Andalusia, Aragon, the Principality of Asturias, the Balearic Islands, the Basque Country, the Canary Islands, Cantabria, Castile-La Mancha, Castile and Leon, Catalonia, Extremadura, Galicia, La Rioja, Madrid, Murcia, Navarre and Valencia.

Regressions were carried out with both fixed and random effects. Since the Hausman test $\left(H_{F R}\right)$ suggests evidence in favor of the fixed effects method, Table (1) shows the results of the estimation using that method. Robust standard errors to heteroskedasticity à la White (1980) are also provided. ${ }^{17}$

Regarding the control variables, in general, similar results to the previous evidence were found. Partisan alignment effects hold with OLS. However, they are weaker when standard errors are corrected by heteroskedasticity. Like Álvarez (2007) and Aray (2016), the more specialized the region, the

\footnotetext{
${ }^{16}$ From 1979 to 1983 , all the regions of Spain were recognized as autonomous communities.

${ }^{17}$ Standard errors corrected by autocorrelation à la Newey and West (1987) were also estimated. In general, results hold and are available upon request.
} 
higher the growth of TFP. The estimator is significant at the $1 \%$ level. A positive significant effect is found for public infrastructure (Mas et al., 1996; Salinas-Jimenez, 2003; Delgado and Álvarez, 2004 and Aray, 2016) while no effect is found for health infrastructure. Strikingly, a negative effect is found for social capital which contrasts with the positive results found by Peiró-Palomino and Tortosa-Ausina (2015) for Spanish provinces (NUTS3). A significant positive effect is found for R\&D capital stock in line with Fernández-Vazquez and Rubiera-Morollon (2013) and Fernández et al. $(2012)$

Let us now concentrate on the variables measuring decentralization. According to the results in Table (1), three out of the five variables capturing the effects of decentralization are significant. Positive effects are found for $\Delta \log \left(F A_{i t}\right)$ and $\Delta \log \left(I A_{i t}^{p u}\right)$, which are significant at the $5 \%$ and $1 \%$ level, respectively, while a negative effect is found for $\Delta \log \left(N R_{i t}\right)$, which is significant at the $5 \%$ level. The results suggest that having greater autonomy in the management of revenues, as well as decision-making power in the allocation of public infrastructure, would increase the TFP growth rate. This result is in line with Tiebout (1956) and Oates (1972, 1999), who attributed a better knowledge of regional needs to regional planners and suggested that they are more efficient in satisfying them. Therefore, increasing autonomy in the management of revenues and expenses would produce higher efficiency in the provision of public goods and services and, probably, higher economic 
growth. However, the results warn of the general increase in decision-making power as captured by the number of responsibilities transferred, which would decrease the TFP growth rate.

The positive effects of $\Delta \log \left(F A_{i t}\right)$ and $\Delta \log \left(I A_{i t}^{p u}\right)$ could support the argument of the politicians who suggest advancing in the management of resources by regions, that is, moving towards a federal state. On the other hand, the negative effect of $\Delta \log \left(N R_{i t}\right)$ supports the argument of a reversal in the decentralization process to return some responsibilities to the central government (i.e., a more centralized state than the current one in order to avoid the duplicity of some functions and the increased bureaucracy of regional institutions).

The results found in this article are in a similar same line of the literature related to Spain that has found positive effects for revenue measures. Moreover, this article finds evidence of an expenditure measure as Carrióni-Silvestre et al. (2008) which is not, however, exclusive for regions with a higher level of competencies according to their classification, but for all regions on average. As a novelty, it is found that more responsibilities seem to have negative effects on economic growth, which might be related to the inefficiency caused by the increase in regional bureaucracy.

While previous evidence has used the growth rate of the regional economy or the growth rate of GDP per capita of the regions as a dependent variable, this article casts new evidence by assuming that the effect of decentralization 
on economic growth accrues through the TFP of the regions.

Moreover, the statistical evidence found in this article might be in line with recent theoretical results suggesting the existence of a threshold in the levels of decentralization. However, the threshold depends on the variable under consideration. Thus, it could be argued that Spanish regions have not reached the threshold for the decentralization of revenues and investment in public infrastructure, suggesting that there would be margins to increase the level of autonomies in such indicators. However, the regions of Spain could be thought to have reached the threshold in the case of tax collection and investment in education and health because no effect is found or they are simply not significant because they actually have no effects. The competencies of education and health are those in which the decentralization process has likely advanced most. In fact, most of the autonomous communities became responsible for these competencies in the early stages of the development of the statutes of autonomies. For that reason, most regions have a nearly 100 per cent share in public investment in education and health. Finally, the results suggest that Spain could have surpassed the threshold of the number of responsibilities transferred to the regions. Remember that Spain is one of the most decentralized countries in Europe along with Germany and Belgium.

In any case, the results could be suggesting that the Spanish state might be near or surrounding the optimal level of decentralization in line with the 
theoretical literature.

\section{Robustness Check}

\subsection{Accounting for Endogeneity}

According to the specification in (2) and equation (3), some control variables and some variables capturing decentralization are likely to be simultaneously determined with the TFP growth rates. Therefore, the results in Table (1) could be affected by potential endogeneity problems. In order to overcome that, we run a two-step least squares estimation (2SLS) considering that all the variables of the model except $\triangle \log \left(N R_{i t}\right)$ and the dummies for partisan alignment are endogenous. These variables could be simultaneously generated with the GDP growth and hence with the TFP growth. The results are shown in Table (2). Two lags of the variables assumed to be endogenous were used as instruments. Notice that $\triangle \log \left(N R_{i t}\right)$ and $\Delta \log \left(I A_{i t}^{e h}\right)$ are significant at the $10 \%$ level and both have negative signs. However, evidence in favor of the hypothesis of endogeneity is weak since the Hausman exogeneity test $\left(H_{E}\right.$ test) does not reject the hypothesis of exogeneity of variables at the $1 \%$ level. Given that the Sargan test does not reject the hypothesis of exogeneity of the instruments either, they are valid instruments. As can be noticed in the subsections below, the evidence against endogeneity is stronger.

An explanation for the finding of weak evidence on the endogeneity of 
the variables might be related to the fact that the variables of interest are shares. Thus, if, for instance, tax collection, in general, depends on the GDP, by calculating the tax share, the GDP is in the numerator and denominator and it would therefore not be affected by the GDP. Similar arguments apply to $\Delta \log \left(F A_{i t}\right), \Delta \log \left(I A_{i t}^{p u}\right)$ and $\Delta \log \left(I A_{i t}^{e h}\right)$. Regarding the control variables related to capital stock, the weak evidence on the endogeneity could be explained by the fact that current investment becomes capital in the next period. Therefore, current capital stock is affected by the previous year's investment and hence the GDP and TFP of the previous period.

\subsection{Estimating Production Functions}

\subsubsection{Estimation of production (1): assuming constant returns to scale}

Departing from (1), an alternative econometric approach is to regress the growth rate of output per efficient worker, $\Delta \log \left(y_{i t}\right)$, on the growth rate of the input $\Delta \log \left(k_{i t}\right)$ and all variables on the right side of $(3)$, as shown in the following equation

$$
\begin{aligned}
\triangle \log \left(y_{i t}\right)= & \alpha \triangle \log \left(k_{i t}\right)+\delta_{i}+\tau_{t}+\sum_{p=0}^{2} \theta_{M p} D M_{i t-p}+\theta_{1} \triangle \log \left(S I_{i t}\right) \\
& +\theta_{2} \triangle \log \left(k_{i t}^{p u}\right)+\theta_{3} \triangle \log \left(k_{i t}^{h c}\right)+\theta_{4} \triangle \log \left(k_{i t}^{s}\right)+\theta_{5} \triangle \log \left(k_{i t}^{r d}\right) \\
& +\beta_{1} \Delta \log \left(T A_{i t}\right)+\beta_{2} \triangle \log \left(F A_{i t}\right)+\beta_{3} \triangle \log \left(I A_{i t}^{p u}\right) \\
& +\beta_{4} \triangle \log \left(I A_{i t}^{e h}\right)+\beta_{5} \triangle \log \left(N R_{i t}\right)+\varepsilon_{i t}
\end{aligned}
$$


Table (3) shows the results of estimating equation (4). As can be seen, the estimations are, in general, very similar to Table (1). The estimate of $\alpha$ is positive and lower than one, as expected, and significant at any conventional level. However, some control variables, such as $\triangle \log \left(k_{i t}^{p u}\right)$ and $\triangle \log \left(k_{i t}^{r d}\right)$, are not significant, which could be explained by that fact that $\triangle \log \left(k_{i t}\right)$ is somehow capturing these variables, at least partially. Regarding the variables of interest, they are still significant and the evidence is stronger when accounting for heteroskedasticity. Evidence of endogeneity of the variables is weaker than in the previous case since the hypothesis of exogeneity of the variables would be rejected only at the $10 \%$ level.

Barro (1999) already stressed that one disadvantage of this approach is the static factor share, $\alpha$. Fortunately, panel data is very useful to overcome that since it is possible to estimate the capital share for each region, $\alpha_{i}$ for $i=1,2, \ldots 17$. Moreover, panel data is very useful for estimating time-varying parameters. Thus, $\alpha_{t}$ for $t=3,4, \ldots 25$ can be estimated. ${ }^{18}$ Notice that, in the first case, the parameters are assumed to vary across regions but are constant over time, while in the second case, the parameters are varying over time but constant across regions.

Table (4) shows the results for the case of assuming different capital shares for the regions, $\alpha_{i}$, but which are constant over time. Appendix shows the autonomous communities associated to subindex $i$. Again, it is

\footnotetext{
${ }^{18}$ Two observations are lost in the estimation.
} 
obtained that the estimates of capital shares are positive, lower than one and significant at the $1 \%$ level for most regions and significant at the $5 \%$ level for all regions. The results for the variables of interest are very similar to the previous one. The hypothesis of equal $\alpha_{i}$ across regions (i.e., $\mathrm{H}_{\alpha_{i}}$ : $\left.\alpha_{1}=\alpha_{2}=\ldots=\alpha_{17}=\alpha\right)$ is tested and was rejected at any conventional level, which supports the argument of Barro (1999). Notice that the exogeneity test of Hausman shows no evidence of endogeneity of the explanatory variables.

Table (5) shows the results assuming time-varying capital share, $\alpha_{t}$. Again it is obtained that the estimates of capital shares are positive, lower than one and in most the cases significant considering up to a $10 \%$ level. The hypothesis of equal capital share over time is constant $\left(H_{\alpha_{t}}\right.$ : $\left.\alpha_{3}=\alpha_{4}=\ldots=\alpha_{25}=\alpha\right)$ is tested and was not rejected when using OLS standard errors at any conventional level, thus suggesting that capital share would be constant over time. However, it is rejected at the $10 \%$ level when standard errors are corrected by heteroskedasticity. As regard the variables of interest, the results, in general, hold and again are stronger when corrected by heteroskedasticity. No evidence of endogeneity is found.

\subsubsection{Estimation of a production function: no constant returns to scale is assumed}

In this subsection, a Cobb-Douglas production function without imposing constant returns to scale is estimated. Thus, a function as follows is assumed

$$
Y_{i t}=B_{i t} K_{i t}^{\alpha_{i}} N_{i t}^{\phi_{i}}
$$


Where $K_{i t}$ is the stock of non-residential productive capital. The twostep approach as Cole and Neumayer (2006) will be used. However, this article goes further by considering that elasticities of output with respect to the inputs vary across regions in line with the above results. Therefore, the following equation is estimated in the first step:

$$
\triangle \log \left(Y_{i t}\right)=\alpha_{i} \triangle \log \left(K_{i t}\right)+\phi_{i} \triangle \log \left(N_{i t}\right)+\mu_{i t},
$$

Where $\mu_{i t}=\triangle \log \left(B_{i t}\right)$. Therefore, a measure of the TFP growth rate can be obtained through an econometric approach by estimating a production function which is an alternative to the growth accounting methodology. Thus, the estimation $\hat{\mu}_{i t}$ can be used as a dependent variable to estimate equation (3) in the second step of the procedure.

Table (6) shows the results for the second step of the estimation. ${ }^{19}$ Notice that, regardless of constant return to scale, the results hold for $\triangle \log \left(I A_{i t}^{p u}\right)$ and $\triangle \log \left(N R_{i t}\right)$. The Hausman test shows no evidence against exogeneity of the explanatory variables. ${ }^{20}$

\footnotetext{
${ }^{19}$ Estimation of the first step was carried out using OLS and 2SLS. Individual coefficient estimates were again positive and lower than one and most of them were significant. The hypothesis of simultaneous constant returns to scale across individuals was estimated and was rejected at any conventional level. Residuals of 2SLS estimations were used in the second step. However, similar results were obtained using the OLS residuals. Results are available upon request.

${ }^{20}$ Estimation assuming time-varying elastiticities of output with respect to the inputs was also carried out. The main results hold and are available upon request.
} 


\subsubsection{Estimation of a production function including public in- frastructure as an input: no constant returns to scale is assumed}

In this subsection, an extended Cobb-Douglas production function accounting for public infrastructure without imposing constant returns to scale in the spirit of Barro (1990) and Aschauer (1989) is estimated. Following these authors, let us assume a production function as follows

$$
Y_{i t}=B_{i t}\left(K_{i t}^{*}\right)^{\alpha_{i}}\left(N_{i t}\right)^{\phi_{i}}\left(K_{i t}^{p u}\right)^{\gamma_{i}}
$$

Where $K_{i t}^{*}$ is the stock of non-residential productive capital without including the public infrastructure provided by the public sector, ${ }^{21} K_{i t}^{p u}$ is the stock of public infrastructure. The following equation is estimated:

$$
\triangle \log \left(Y_{i t}\right)=\alpha_{i} \triangle \log \left(K_{i t}^{r}\right)+\phi_{i} \triangle \log \left(N_{i t}\right)+\gamma_{i} \triangle \log \left(K_{i t}^{p u}\right)+\mu_{i t},
$$

Where $\mu_{i t}=\triangle \log \left(B_{i t}\right)$ is the disturbance. Again, the two-step approach is followed.

Table (7) shows the results for the second step of the estimation. ${ }^{22}$ The results only hold for $\triangle \log \left(I A_{i t}^{p u}\right)$ when using OLS, while $\triangle \log \left(N R_{i t}\right)$ is also significant at the $10 \%$ level when using the standard error corrected by

\footnotetext{
${ }^{21}$ Thus, items 1.2.1, 1.2.2, 1.2.3, 1.2.4, 1.2.5, and 1.2.6 according to the clasification by assets of the productive capital were substracted.

${ }^{22}$ Estimation of the first step was carried out using OLS and 2SLS and is available upon request. Residuals of 2SLS estimations were used in the second step. However, similar results were obtained using the OLS residuals.
} 
heteroskedasticity. The Hausman test shows no evidence against exogeneity of the explanatory variables.

\section{Conclusions}

This article casts new evidence on the effects of decentralization on economic growth assuming that such effects accrue through total factor productivity $(T F P)$. We try to overcome the recent criticisms of the empirical approaches regarding the proper measures of variables capturing decentralization. Thus, five measures of decentralization are proposed to capture tax autonomy, financial autonomy, public investment autonomy and the general decisionmaking power. A behavioral equation for the growth rate of $T F P$ is specified to allow a nonlinear relationship between decentralization and economic growth. The empirical evidence focused on the Spanish case at two layers of government (central and regional) during the 1986-2010 period and all the autonomous communities of Spain. Panel data estimation is applied.

The empirical results show that increasing the regions' financial autonomy, as well as a greater share of regional investment in public infrastructure, positively affect the TFP growth rate, which could support the argument of the politicians who suggest moving towards a federal state. However, the TFP growth rate is negatively affected by the number of responsibilities or competencies assumed by the autonomous communities, which supports the argument of others politicians regarding a reversal in the decentralization 
process. Moreover, the empirical evidence could be suggesting that the Spanish state might be near or surrounding the optimal level of decentralization. The results are robust to different estimation methods, measures of TFP and constant and non-constant returns to scale. 


\section{References}

[1] Akai, N., Nishimura, Y. and Sakata, M. (2007). Complementarity, fiscal decentralization and economic growth. Economics of Governance 8, $339-362$.

[2] Álvarez, A. (2007). Decomposing Regional Productivity Growth Using an Aggregate Production Frontier. Annals of Regional Science 41, 431441.

[3] Aray, H. (2016). Partisan Alignment Effects on Total Factor Productivity. Regional Studies 50, 154-167.

[4] Aschauer, D. A. (1989). Is Public Expenditure Productive? Journal of Monetary Economics 23, 177-200.

[5] Barro, R. (1990). Government Spending in a Simple Model of Endogenous Economic Growth. Journal of Political Economy 98, 103125.

[6] Barro, R. (1999). Notes on Growth Accounting. Journal of Economic Growth 4, 119-137.

[7] Baskaran, T., Feld, L.P. and Schnellenbach, J. (2016). Fiscal Federalism, Decentralization and Economic Growth: A Meta-Analysis. Economic Inquiry 54, 1445-1463. 
[8] Cantarero, D. and Pérez-González, P. (2009). Fiscal Decentralization and Economic Growth: Evidence from Spanish Regions. Public Budgeting and Finance 29, 24-44.

[9] Carrión-i-Silvestre, J. L., Espasa, M. and Mora, T. (2008). Fiscal Decentralization and Economic Growth in Spain. Public Finance Review $36,194-218$.

[10] Chu, A. C. and Yang, C. C. (2012). Fiscal centralization versus decentralization: Growth and welfare effects of spillovers, Leviathan taxation, and capital mobility. Journal of Urban Economics 71, 177188.

[11] Cole, M.A. and Neumayer, E. (2006). The Impact of Poor Health on Total Factor Productivity. Journal of Development Studies 42, 918-938.

[12] Delgado, M. J. and I. Álvarez. (2004). Infraestructuras y Eficiencia Técnica: un Análisis de Técnicas Frontera. Revista de Economía Aplicada 12, 65-82.

[13] Dixit, A. (2009). Governance Institutions and Economic Activity. American Economic Review 99, 5-24.

[14] Fernández, N., Martínez, V. and Sanchez-Robles, B. (2012). R\&D And Growth in the Spanish Regions: An Empirical Approximation. International Journal of Business and Social Science 3, 22-31. 
[15] Fernandez-Vazquez, E. and Rubiera-Morollon, F. (2013). Estimating regional variations of $\mathrm{R} \& \mathrm{D}$ effects on productivity growth by entropy econometrics. Spatial Economic Analysis 8, 54-70.

[16] Gil-Serrate, R., and López-Laborda, J. (2006). Revenue Decentralization and Economic Growth in the Spanish Autonomous Communities. Unpublished Manuscript, University of Zaragoza.

[17] Gil-Serrate, R., López-Laborda, J. and Mur, J. (2011). Revenue autonomy and regional growth: an analysis of the 25-year process of fiscal decentralisation in Spain. Environment and Planning A 43, 26262648 .

[18] Hall, R. E. and Jones, C. I. (1999). Why do Some Countries Produce so Much More Output per Worker than Others? The Quarterly Journal of Economics 114, 83-16.

[19] Ligthart, J. E. and van Oudheusden, P. (2016). The Fiscal Decentralization and Economic Growth Nexus Revisited. Fiscal Studies, DOI: $10.1111 / 1475-5890.12099$.

[20] Martínez Galarraga, J., Paluzie, E., Pons, J. and Tirado-Fabregat, D. A. (2008). Agglomeration and labour productivity in Spain over the long term. Cliometrica 2, 195-212. 
[21] Martínez-Vázquez, J., Lago-Peñas, S. and Sacchi, A. (2015). The Impact of Fiscal Decentralization: a Survey. GEN Working Paper A 2015-5.

[22] Martínez-Vázquez, J. and McNab, R. (2003). Fiscal Decentralization and Economic Growth. World Development 31, 1597-1616.

[23] Mas, M., Maudos, J., Pérez, F. and E. Uriel. (1996). Infrastructure and Productivity in the Spanish Regions. Regional Studies 30, 641-649.

[24] Moreno, L. (2002). Decentralization in Spain. Regional Studies 36, 399 408.

[25] Newey, W. and West, K. (1987). A Simple, Positive Definite, Heteroskedasticity and Autocorrelation Consistent Covariance Matrix. Econometrica 55(3), 703-708.

[26] North, D. C. (1990). Institutions, Institutional Change and Economic Performance. Cambridge University Press.

[27] Oates, W. E. (1972) Fiscal Federalism. New York: Harcourt Brace Jovanovich.

[28] Oates. W. E. (1999). An Essay on Fiscal Federalism. Journal of Economic Literature 37, 1120-1149. 
[29] Ogawa, H. and Yakita, S. (2009). Equalization Transfers, Fiscal Decentralization, and Economic Growth. FinanzArchiv: Public Finance Analysis 65, 122-140.

[30] Peiró-Palomino, J. and Tortosa-Ausina, E. (2015). Social Capital, Investment and Economic Growth: Some Evidence for Spanish Provinces. Spatial Economic Analysis 10, 102-126.

[31] Rodrick, D., Subramnian, A. and F. Trebbi. (2004). Institutions Rules: The Primacy of Institutions over Geography and Integration in Economic Development. Journal of Economic Growth 9, 131-165.

[32] Salinas-Jimenez, M. (2003). Efficiency and TFP Growth in the Spanish Regions: The Role of Human and Public Capital. Growth and Change 34, 157-174.

[33] Tiebout, C. M. (1956). A Pure Theory of Local Expenditures. The Journal of Political Economy, 64, 416-424.

[34] White, H. (1980). A Heteroskedasticity-Consistent Covariance Matrix Estimator and A Direct Test for Heteroskedasticity. Econometrica, 48, 817-838.

[35] Xie, D., Zou, H. and Davoodi, H. (1999). Fiscal Decentralization and Economic Growth in the United States. Journal of Urban Economics $45,228-239$. 


\section{Appendix: Autonomous Communities}

1. Andalusia

2. Aragon

3. The Principality of Asturias

4. The Balearic Islands

5. The Canary Islands

6. Cantabria

7. Castile and Leon

8. Castile-La Mancha

9. Catalonia

10. Valencia

11. Extremadura

12. Galicia

13. Madrid

14. Murcia

15. Navarre

16. The Basque Country

17. La Rioja 
Table 1: Panel data regression for the growth rate of TFP with fixed effects

\begin{tabular}{|c|c|c|c|}
\hline & Estimates & Standard Errors & Standard Errors à la White \\
\hline$D M_{i t}$ & 0.0090 & $0.0036^{* *}$ & 0.0061 \\
\hline$D M_{i t-1}$ & -0.0094 & $0.0043^{* *}$ & 0.0060 \\
\hline$D M_{i t-2}$ & -0.0070 & $0.0035^{* *}$ & $0.0031^{* *}$ \\
\hline$\triangle \log \left(S I_{i t}\right)$ & 0.0133 & $0.0039^{* * *}$ & $0.0032^{* * *}$ \\
\hline$\triangle \log \left(k_{i t}^{p u}\right)$ & 0.3556 & $0.0458^{* * *}$ & $0.0527^{* * *}$ \\
\hline$\triangle \log \left(k_{i t}^{h c}\right)$ & 0.0371 & 0.0237 & 0.0236 \\
\hline$\triangle \log \left(k_{i t}^{s}\right)$ & -0.0326 & $0.0110^{* * *}$ & $0.0102^{* * *}$ \\
\hline$\triangle \log \left(k_{i t}^{r d}\right)$ & 0.0665 & $0.0240^{* * *}$ & $0.0278^{* *}$ \\
\hline$\triangle \log \left(T A_{i t}\right)$ & -0.0021 & 0.0075 & 0.0072 \\
\hline$\triangle \log \left(F A_{i t}\right)$ & 0.0116 & $0.0057^{* *}$ & $0.0051^{* *}$ \\
\hline$\triangle \log \left(I A_{i t}^{p u}\right)$ & 0.0132 & $0.0041^{* * *}$ & $0.0039^{* * *}$ \\
\hline$\triangle \log \left(I A_{i t}^{e h}\right)$ & -0.0042 & 0.0029 & 0.0027 \\
\hline$\triangle \log \left(N R_{i t}\right)$ & -0.0477 & $0.0225^{* *}$ & $0.0203^{* *}$ \\
\hline$H_{F R}$ & \multicolumn{3}{|c|}{$73.7811(0.0000)$} \\
\hline$R^{2}$ & \multicolumn{3}{|c|}{0.5844} \\
\hline
\end{tabular}


Table 2: 2SLS Panel Data Regression for the growth rate of TFP with fixed effects

\begin{tabular}{lrl}
\hline \hline & 2SLS Estimation & Standard Errors \\
\hline$D M_{i t}$ & 0.0131 & $0.0064^{* *}$ \\
$D M_{i t-1}$ & -0.0097 & 0.0073 \\
$D M_{i t-2}$ & -0.0115 & 0.0073 \\
$\triangle \log \left(S I_{i t}\right)$ & 0.0192 & 0.0207 \\
$\triangle \log \left(k_{i t}^{p u}\right)$ & 0.1233 & 0.1951 \\
$\triangle \log \left(k_{i t}^{h c}\right)$ & 0.1297 & $0.0753^{*}$ \\
$\triangle \log \left(k_{i t}^{s}\right)$ & 0.0874 & 0.0879 \\
$\triangle \log \left(k_{i t}^{r d}\right)$ & 0.0612 & 0.0844 \\
$\triangle \log \left(T A_{i t}\right)$ & 0.0186 & 0.0314 \\
$\triangle \log \left(F A_{i t}\right)$ & -0.0534 & 0.0405 \\
$\triangle \log \left(I A_{i t}^{p u}\right)$ & 0.0214 & 0.0244 \\
$\triangle \log \left(I A_{i t}^{e h}\right)$ & -0.0211 & $0.0127^{*}$ \\
$\triangle \log \left(N R_{i t}\right)$ & -0.0765 & $0.0450^{*}$ \\
\hline$H_{E}$ & $18.3079(0.0318)$ \\
$\operatorname{Sargan} T e s t$ & $8.0362(0.5305)$ \\
$R^{2}$ & 0.1361 \\
\hline \hline$* * * * *, *$ & Significant at $1 \%, 5 \%$ and $10 \%$ levels, respectively.
\end{tabular}


Table 3: Panel Data Regression for the growth rate of GDP per efficient worker with fixed effects

\begin{tabular}{lrll}
\hline \hline & Estimates & Standard Errors & Standard Errors à la White \\
\hline$\triangle \log \left(k_{1 t}\right)$ & 0.6177 & $0.0927^{* * *}$ & $0.1059^{* * *}$ \\
$D M_{i t}$ & 0.0097 & $0.0036^{* * *}$ & 0.0061 \\
$D M_{i t-1}$ & -0.0077 & $0.0042^{*}$ & 0.0059 \\
$D M_{i t-2}$ & -0.0062 & $0.0035^{*}$ & $0.0031^{* *}$ \\
$\triangle \log \left(S I_{i t}\right)$ & 0.0128 & $0.0038^{* * *}$ & $0.0030^{* * *}$ \\
$\triangle \log \left(k_{i t}^{p u}\right)$ & 0.1171 & 0.0732 & $0.0702^{*}$ \\
$\triangle \log \left(k_{i t}^{h c}\right)$ & 0.0109 & 0.0239 & 0.0238 \\
$\triangle \log \left(k_{i t}^{s}\right)$ & -0.0293 & $0.0108^{* * *}$ & $0.0110^{* * *}$ \\
$\triangle \log \left(k_{i t}^{r d}\right)$ & 0.0290 & 0.0252 & 0.0300 \\
$\triangle \log \left(T A_{i t}\right)$ & -0.0012 & 0.0073 & 0.0075 \\
$\triangle \log \left(F A_{i t}\right)$ & 0.0109 & $0.0055^{*}$ & $0.0046^{* *}$ \\
$\triangle \log \left(I A_{i t}^{p u}\right)$ & 0.0084 & $0.0042^{* *}$ & $0.0037^{* *}$ \\
$\triangle \log \left(I A_{i t}^{e h}\right)$ & -0.0024 & 0.0029 & 0.0027 \\
$\triangle \log \left(N R_{i t}\right)$ & -0.0422 & $0.0220^{*}$ & $0.0120^{* *}$ \\
\hline$H_{E}$ & $17.4176(0.0656)$ & \\
$\operatorname{Sargan} T e s t$ & $10.9130(0.3643)$ & \\
$R^{2}$ & 0.7148 & & \\
\hline \hline$* * *, * * *$ & Significant at $1 \%, 5 \%$ and $10 \%$ levels, respectively.
\end{tabular}


Table 4: Panel Data Regression for the growth rate of GDP per efficient worker with fixed effects and different capital shares across regions

\begin{tabular}{|c|c|c|c|}
\hline & Estimates & Standard Errors & Standard Errors à la White \\
\hline$\triangle \log \left(k_{1 t}\right)$ & 0.4581 & $0.1322^{* * *}$ & $0.1135^{* * *}$ \\
\hline$\triangle \log \left(k_{2 t}\right)$ & 0.5221 & $0.1423^{* * *}$ & $0.1136^{* * *}$ \\
\hline$\triangle \log \left(k_{3 t}\right)$ & 0.7817 & $0.1459^{* * *}$ & $0.2035^{* * *}$ \\
\hline$\triangle \log \left(k_{4 t}\right)$ & 0.7209 & $0.1103^{* * *}$ & $0.1281^{* * *}$ \\
\hline$\triangle \log \left(k_{5 t}\right)$ & 0.5143 & $0.1258^{* * *}$ & $0.1681^{* * *}$ \\
\hline$\triangle \log \left(k_{6 t}\right)$ & 0.5460 & $0.1420^{* * *}$ & $0.1327^{* * *}$ \\
\hline$\triangle \log \left(k_{7 t}\right)$ & 0.7428 & $0.1733^{* * *}$ & $0.1244^{* * *}$ \\
\hline$\triangle \log \left(k_{8 t}\right)$ & 0.3158 & $0.1411^{* *}$ & $0.1176^{* * *}$ \\
\hline$\triangle \log \left(k_{9 t}\right)$ & 0.4085 & $0.1438^{* * *}$ & $0.1210^{* * *}$ \\
\hline$\triangle \log \left(k_{10 t}\right)$ & 0.4314 & $0.1400^{* * *}$ & $0.1212^{* * *}$ \\
\hline$\triangle \log \left(k_{11 t}\right)$ & 0.5483 & $0.1316^{* * *}$ & $0.0915^{* * *}$ \\
\hline$\triangle \log \left(k_{12 t}\right)$ & 0.5852 & $0.1685^{* * *}$ & $0.1349^{* * *}$ \\
\hline$\triangle \log \left(k_{13 t}\right)$ & 0.4961 & $0.1378^{* * *}$ & $0.1276^{* * *}$ \\
\hline$\triangle \log \left(k_{14 t}\right)$ & 0.4807 & $0.1247^{* * *}$ & $0.1409^{* * *}$ \\
\hline$\triangle \log \left(k_{15 t}\right)$ & 0.2954 & $0.1422^{* *}$ & $0.1348^{* *}$ \\
\hline$\triangle \log \left(k_{16 t}\right)$ & 0.3707 & $0.1651^{* *}$ & $0.1433^{* * *}$ \\
\hline$\triangle \log \left(k_{17 t}\right)$ & 0.9507 & $0.1429^{* * *}$ & $0.2989^{* * *}$ \\
\hline$D M_{i t}$ & 0.0098 & $0.0035^{* * *}$ & $0.0056^{*}$ \\
\hline$D M_{i t-1}$ & -0.0073 & $0.0041^{*}$ & 0.0053 \\
\hline$D M_{i t-2}$ & 0.0043 & 0.0034 & 0.0029 \\
\hline$\triangle \log \left(S I_{i t}\right)$ & 0.0118 & $0.0038^{* * *}$ & $0.0027^{* * *}$ \\
\hline$\triangle \log \left(k_{i t}^{p u}\right)$ & 0.1805 & $0.0734^{* *}$ & $0.0747^{* *}$ \\
\hline$\triangle \log \left(k_{i t}^{h c}\right)$ & -0.0033 & 0.0241 & 0.0311 \\
\hline$\triangle \log \left(k_{i t}^{s}\right)$ & -0.0306 & $0.0108^{* *}$ & $0.0109^{* * *}$ \\
\hline$\triangle \log \left(k_{i t}^{r d}\right)$ & 0.0401 & 0.0256 & 0.0307 \\
\hline$\triangle \log \left(T A_{i t}\right)$ & -0.0013 & 0.0072 & 0.0076 \\
\hline$\triangle \log \left(F A_{i t}\right)$ & 0.0106 & $0.0054^{*}$ & $0.0046^{* *}$ \\
\hline$\triangle \log \left(I A_{i t}^{p u}\right)$ & 0.0094 & $0.0041^{* *}$ & $0.0038^{* *}$ \\
\hline$\triangle \log \left(I A_{i t}^{e h}\right)$ & -0.0015 & 0.0029 & 0.0027 \\
\hline$\triangle \log \left(N R_{i t}\right)$ & -0.0367 & $0.0218^{*}$ & $0.0169^{* *}$ \\
\hline$H^{\alpha_{i}}$ & & $2.4670(0.0015)$ & $47.9699(0.0000)$ \\
\hline$H_{E}$ & $26.7222(0.4240)$ & & \\
\hline Sargan Test & $12.0867(0.9907)$ & & \\
\hline$R^{2}$ & 0.7462 & & \\
\hline
\end{tabular}

***,**,*: Significant at 1\%, $5 \%$ and $10 \%$ levels, respectively. 
Table 5: Panel Data Regression for the growth rate of GDP per efficient worker with fixed effects and time-varying capital shares

\begin{tabular}{|c|c|c|c|}
\hline & Estimates & Standard Errors & Standard Errors à la White \\
\hline$\triangle \log \left(k_{i 3}\right)$ & 0.8621 & $0.2264^{* * *}$ & $0.1706^{* * *}$ \\
\hline$\triangle \log \left(k_{i 4}\right)$ & 0.4066 & 0.2476 & $0.2111^{*}$ \\
\hline$\triangle \log \left(k_{i 5}\right)$ & 0.8976 & $0.1509^{* * *}$ & $0.3240^{* * *}$ \\
\hline$\triangle \log \left(k_{i 6}\right)$ & 0.4175 & $0.1875^{* *}$ & $0.2071^{* *}$ \\
\hline$\triangle \log \left(k_{i 7}\right)$ & 0.5274 & $0.2400^{* *}$ & 0.3261 \\
\hline$\triangle \log \left(k_{i 8}\right)$ & 0.4472 & $0.2394^{*}$ & $0.1668^{* * *}$ \\
\hline$\triangle \log \left(k_{i 9}\right)$ & 0.7167 & $0.1852^{* * *}$ & $0.1369^{* * *}$ \\
\hline$\triangle \log \left(k_{i 10}\right)$ & 0.5936 & $0.2256^{* * *}$ & $0.1528^{* * *}$ \\
\hline$\triangle \log \left(k_{i 11}\right)$ & 0.5438 & $0.2250^{* *}$ & $0.1454^{* * *}$ \\
\hline$\triangle \log \left(k_{i 12}\right)$ & 0.5642 & $0.1789^{* * *}$ & $0.1589^{* * *}$ \\
\hline$\triangle \log \left(k_{i 13}\right)$ & 0.2860 & 0.3093 & 0.1850 \\
\hline$\triangle \log \left(k_{i 14}\right)$ & 0.7262 & $0.2184^{* * *}$ & $0.2466^{* * *}$ \\
\hline$\triangle \log \left(k_{i 15}\right)$ & 0.4451 & $0.2473^{*}$ & $0.1651^{* * *}$ \\
\hline$\triangle \log \left(k_{i 16}\right)$ & 0.3395 & 0.2557 & $0.1437^{* *}$ \\
\hline$\triangle \log \left(k_{i 17}\right)$ & 0.5430 & $0.2493^{* *}$ & $0.1918^{* * *}$ \\
\hline$\triangle \log \left(k_{i 18}\right)$ & 0.2498 & 0.2413 & 0.2113 \\
\hline$\triangle \log \left(k_{i 19}\right)$ & 0.3656 & 0.2455 & $0.1131^{* * *}$ \\
\hline$\triangle \log \left(k_{i 20}\right)$ & 0.7610 & $0.1806^{* * *}$ & $0.1459^{* * *}$ \\
\hline$\triangle \log \left(k_{i 21}\right)$ & 0.4326 & 0.3431 & $0.2437^{*}$ \\
\hline$\triangle \log \left(k_{i 22}\right)$ & 0.4841 & $0.2796^{*}$ & $0.1289^{* * *}$ \\
\hline$\triangle \log \left(k_{i 23}\right)$ & 0.7462 & $0.2186^{* * *}$ & $0.1612^{* * *}$ \\
\hline$\triangle \log \left(k_{i 24}\right)$ & 0.4755 & $0.2348^{* *}$ & $0.2780^{*}$ \\
\hline$\triangle \log \left(k_{i 25}\right)$ & 0.5049 & $0.2091^{* *}$ & $0.1162^{* * *}$ \\
\hline$D M_{i t}$ & 0.0105 & $0.0037^{* * *}$ & $0.0061^{*}$ \\
\hline$D M_{i t-1}$ & -0.0087 & $0.0044^{* *}$ & 0.0056 \\
\hline$D M_{i t-2}$ & -0.0049 & 0.0036 & 0.0031 \\
\hline$\triangle \log \left(S I_{i t}\right)$ & 0.0129 & $0.0040^{* * *}$ & $0.0029^{* * *}$ \\
\hline$\triangle \log \left(k_{i t}^{p u}\right)$ & 0.1370 & $0.0767^{*}$ & $0.0748^{*}$ \\
\hline$\triangle \log \left(k_{i t}^{h c}\right)$ & 0.0152 & 0.0255 & 0.0229 \\
\hline$\triangle \log \left(k_{i t}^{s}\right)$ & -0.0317 & $0.0114^{* * *}$ & $0.0111^{* * *}$ \\
\hline$\triangle \log \left(k_{i t}^{r d}\right)$ & 0.0262 & 0.0261 & 0.0286 \\
\hline$\triangle \log \left(T A_{i t}\right)$ & -0.0016 & 0.0075 & 0.0075 \\
\hline$\triangle \log \left(F A_{i t}\right)$ & 0.0094 & 0.0056 & $0.0047^{* *}$ \\
\hline$\triangle \log \left(I A_{i t}^{p u}\right)$ & 0.0092 & $0.0043^{* *}$ & $0.0037^{* *}$ \\
\hline$\triangle \log \left(I A_{i t}^{e h}\right)$ & -0.0027 & 0.0030 & 0.0027 \\
\hline$\triangle \log \left(N R_{i t}\right)$ & -0.0451 & $0.0232^{*}$ & $0.0208^{* *}$ \\
\hline$H^{\alpha} t$ & & $0.8803(0.6215)$ & $32.2257(0.0736)$ \\
\hline$H_{E}$ & \multicolumn{2}{|c|}{$29.8793(0.5235)$} & \\
\hline Sargan Test & & $389(0.9981)$ & \\
\hline$R^{2}$ & \multicolumn{2}{|l|}{0.7314} & \\
\hline
\end{tabular}

***,**,* : Significant at 1\%, 5\% and 10\% levels, respectively. 
Table 6: Panel Data Regression for an alternative measure of TFP with fixed effects: no constant returns to scale is assumed

\begin{tabular}{lrll}
\hline & Estimates & Standard Errors & Standard Errors à la White \\
\hline$D M_{i t}$ & 0.0108 & $0.0034^{* * *}$ & $0.0062^{*}$ \\
$D M_{i t-1}$ & -0.0082 & $0.0038^{* *}$ & 0.0060 \\
$D M_{i t-2}$ & -0.0043 & 0.0030 & 0.0028 \\
$\triangle \log \left(S I_{i t}\right)$ & 0.0125 & $0.0034^{* * *}$ & $0.0030^{* * *}$ \\
$\triangle \log \left(k_{i t}^{\text {put }}\right)$ & 0.1802 & $0.0397^{* * *}$ & $0.0453^{* * *}$ \\
$\triangle \log \left(k_{i t}^{h c}\right)$ & 0.0056 & 0.0207 & 0.0230 \\
$\triangle \log \left(k_{i t}^{s}\right)$ & -0.0055 & 0.0100 & 0.0087 \\
$\triangle \log \left(k_{i t}^{r d}\right)$ & 0.0306 & 0.0212 & 0.0246 \\
$\triangle \log \left(T A_{i t}\right)$ & -0.0049 & 0.0067 & 0.0064 \\
$\triangle \log \left(F A_{i t}\right)$ & 0.0048 & 0.0049 & 0.0041 \\
$\triangle \log \left(I A_{i t}^{p u}\right)$ & 0.0089 & $0.0036^{* *}$ & $0.0033^{* * *}$ \\
$\triangle \log \left(I A_{i t}^{e h}\right)$ & -0.0014 & 0.0026 & 0.0025 \\
$\triangle \log \left(N R_{i t}\right)$ & -0.0332 & $0.0195^{*}$ & $0.0174^{*}$ \\
\hline$H_{E}$ & $5.6916(0.7703)$ & \\
$\operatorname{Sargan} T e s t$ & $5.6326(0.7760)$ & \\
$R^{2}$ & 0.4951 & \\
\hline \hline
\end{tabular}

${ }^{* * *, * *, *}$ : Significant at 1\%,5\% and $10 \%$ levels, respectively. 
Table 7: Panel Data Regression with fixed effects for an alternative measure of TFP and considering public infrastructure as an input: no constant returns to scale is assumed

\begin{tabular}{lrll}
\hline \hline & Estimates & Standard Errors & Standard Errors à la White \\
\hline$D M_{i t}$ & 0.0106 & $0.0034^{* * *}$ & $0.0057^{*}$ \\
$D M_{i t-1}$ & -0.0063 & 0.0038 & 0.0056 \\
$D M_{i t-2}$ & -0.0042 & 0.0030 & 0.0028 \\
$\triangle \log \left(S I_{i t}\right)$ & 0.0110 & $0.0033^{* * *}$ & $0.0029^{* * *}$ \\
$\triangle \log \left(k_{i t}^{p u}\right)$ & 0.2297 & $0.0394^{* * *}$ & $0.0442^{* * *}$ \\
$\triangle \log \left(k_{i t}^{h c}\right)$ & -0.0049 & 0.0205 & 0.0239 \\
$\triangle \log \left(k_{i t}^{s}\right)$ & -0.0015 & 0.0099 & 0.0090 \\
$\triangle \log \left(k_{i t}^{r d}\right)$ & -0.0064 & 0.0210 & 0.0220 \\
$\triangle \log \left(T A_{i t}\right)$ & -0.0048 & 0.0066 & 0.0062 \\
$\triangle \log \left(F A_{i t}\right)$ & 0.0048 & 0.0049 & 0.0040 \\
$\triangle \log \left(I A_{i t}^{p u}\right)$ & 0.0075 & $0.0035^{* *}$ & $0.0033^{* *}$ \\
$\triangle \log \left(I A_{i t}^{e h}\right)$ & -0.0001 & 0.0026 & 0.0026 \\
$\triangle \log \left(N R_{i t}\right)$ & -0.0304 & 0.0193 & $0.0165^{*}$ \\
\hline$H_{E}$ & $6.1912(0.7206)$ & \\
$\operatorname{Sargan} T e s t$ & $4.0937(0.9051)$ & \\
$R^{2}$ & 0.4614 & \\
\hline \hline ***,***$:$ Significant at $1 \%, 5 \%$ and $10 \%$ levels, respectively.
\end{tabular}

